\title{
Class II malocclusion treatment with the Herbst appliance in patients after the growth peak
}

\author{
José Carlos de Castro Alvares ${ }^{1}$, Rodrigo Hermont Cançado², Fabrício Pinelli Valarelli², \\ Karina Maria Salvatore de Freitas ${ }^{3}$, Christian Zamberlan Angheben ${ }^{1}$
}

\begin{abstract}
Objective: The objective of this study was to evaluate dentoskeletal effects in the treatment of Class II malocclusion performed with the Herbst appliance in patients at post-peak stage of growth. Methods: The sample consisted of 16 patients with Class II malocclusion and average initial and final ages of 14.04 (ranging from 11.50 to 35.66) and 17.14 (ranging from 13.68 to 38.64) years, respectively, who were treated for an mean time of 2.52 years. Lateral cephalograms were obtained at treatment onset $\left(\mathrm{T}_{1}\right)$ and completion $\left(\mathrm{T}_{2}\right)$ to evaluate the effects of therapy. Initial dental casts were also used to evaluate the overjet and the anteroposterior severity of molar relationship at treatment onset. The cephalometric changes between initial and final stages were compared by means of the non-parametric Wilcoxon test. Results: The results showed that the Herbst appliance did not promote significant changes in the maxillary component and the effective length of the mandible significantly increased without improving the maxillomandibular relationship. Changes in the maxillary and mandibular dentoalveolar components revealed that the maxillary incisors exhibited retrusion and lingual tipping, while the mandibular incisors presented increased protrusion and buccal tipping. The dental relationships exhibited significant improvements with the treatment. Conclusion: Based on the present results, it was concluded that the effects of treatment performed with the Herbst appliance in patients at post-peak stage of growth are predominantly of dentoalveolar nature.
\end{abstract}

Keywords: Angle Class II malocclusion. Head circumference. Functional orthodontic appliance.

Objetivo: avaliar os efeitos dentoesqueléticos do tratamento da má oclusão de Classe II com o aparelho de Herbst em pacientes que se encontravam na fase pós-pico de crescimento. Métodos: a amostra consistiu de 16 pacientes com má oclusão de Classe II com medianas das idades inicial e final de 14,04 (amplitude 11,50 - 35,66) e 17,14 anos (amplitude 13,68 - 38,64), respectivamente, que foram tratados por um período médio de 2,52 anos. Telerradiografias em norma lateral foram obtidas ao início e final do tratamento para avaliar as alterações decorrentes do tratamento. Os modelos de gesso iniciais foram utilizados para avaliar o trespasse horizontal e a severidade da relação anteroposterior existente entre os molares ao início do tratamento. As alterações cefalométricas entre as fases inicial e final foram comparadas pelo teste não-paramétrico de Wilcoxon. Resultados: os resultados mostraram que o aparelho de Herbst não promoveu alterações significativas no componente maxilar, o comprimento efetivo da mandíbula aumentou significativamente, sem promover uma melhoria da relação maxilomandibular. As alterações dos componentes dentoalveolares superiores e inferiores mostraram que os incisivos superiores apresentaram uma retrusão e inclinação lingual, ao passo que os incisivos inferiores evidenciaram um aumento na protrusão e inclinação para vestibular. As relações dentárias apresentaram uma melhora significativa com o tratamento. Conclusão: com base nos resultados desse trabalho, concluiu-se que os efeitos da terapia com o aparelho de Herbst em pacientes na fase pós-pico de crescimento são de natureza predominantemente dentoalveolar.

Palavras-chave: Má oclusão de Angle Classe II. Circunferência craniana. Aparelhos ortodônticos funcionais. Adolescente.

" The patient displayed in this article previously approved the use of her facial and intraoral photographs.

${ }^{1} \mathrm{MSc}$ in Orthodontics, Faculdade Ingá.

${ }^{2}$ Adjunct Professor of the Masters Course in Orthodontics at Faculdade Ingá.

${ }^{3}$ Postdoctoral in Orthodontics, University of Toronto.
How to cite this article: Alvares JCC, Cançado RH, Valarelli FP, Freitas KMS, Angheben CZ. Class II malocclusion treatment with the Herbst appliance in patients after the growth peak. Dental Press J Orthod. 2013 Sept-Oct;18(5):38-45.

Submitted: January 17, 2012 - Revised and accepted: May 14, 2012

" The authors report no commercial, proprietary or financial interest in the products or companies described in this article.

Contact address: Rodrigo Hermont Cançado

Rua do Amparo, 100 - Centro - Diamantina/MG - Brazil

CEP: 39100-000 - E-mail: rohercan@uol.com.br 


\section{INTRODUCTION}

The Herbst appliance has been widely used for treating Class II malocclusions due to its great effectiveness. ${ }^{10}$ Besides allowing stimulation of mandibular growth, the treatment performed with the Herbst appliances promotes redirecting of maxillary growth, mesial movement of mandibular teeth and distal movement of maxillary teeth. ${ }^{9}$ All the aforementioned factors are relevant for both treatment and correction of the Class II malocclusion.

Most studies evaluating the skeletal and dental effects of the Herbst appliances are conducted in patients at the pre-peak stage of growth. ${ }^{8,9,20,21}$ On the other hand, studies on the Herbst appliance in patients at the postpeak stage of growth have been widely accepted by the orthodontic community, due to the fact that it may influence the growth of bone bases within a shorter period of time. ${ }^{13,17,18}$ However, these studies are less frequent in the scientific literature. ${ }^{1,4,11}$

The objective of this study was to evaluate skeletal and dental effects of the Herbst appliance for treating Class II malocclusion in patients at the post-peak stage of growth.

\section{MATERIAL AND METHODS \\ Material}

This clinical study was approved by the Research Ethics Committee (REC) and all patients signed an informed consent form authorizing the use of their orthodontic records for research purposes. The sample was retrospectively selected and initially comprised all patients with Class II malocclusion treated by one of the authors using the Herbst with Cantilever Bite Jumper (CBJ) appliance, combined with fixed appliances (Fig 1). A total of 28 patients were initially selected, among which 16 were selected to compose the sample according to the following inclusion criteria: 1) Patients without previous orthodontic treatment; 2) No tooth losses up to the permanent first molars; 3) Complete orthodontic records at the onset $\left(\mathrm{T}_{1}\right)$ and completion $\left(\mathrm{T}_{2}\right)$ of orthodontic treatment; 4) Patients at post-peak stage of growth at treatment onset, as analyzed on carpal radiographs; 5) The treatment of all patients should be performed without extraction of permanent teeth.

The sample consisted of 32 lateral cephalograms obtained at the onset $\left(\mathrm{T}_{1}\right)$ and at the completion of the orthodontic treatment $\left(\mathrm{T}_{2}\right)$, and 16 dental casts obtained at the onset of the treatment $\left(\mathrm{T}_{1}\right)$ of 16 patients (10 females and 6 males) with Class II malocclusion (14 patients with Class II, division 1 malocclusion; and 2 patients with Class II, division 2 malocclusion). These patients presented median initial and final ages of 14.04 (interquartile deviation of 3.68; amplitude of 11.50-35.66) and 17.14 (interquartile deviation of 4.07; amplitude of 13.68-38.64) years, respectively, and were treated for an mean period of 2.52 years $(\mathrm{SD}=1.00)$. They also presented mean overjet of $6.7 \mathrm{~mm}$, evaluated on the initial dental casts $\left(\mathrm{T}_{1}\right)$. Considering the severity of anteroposterior relationship between the dental arches, four patients presented $1 / 2$ Class II, four patients presented $3 / 4$ Class II and eight patients had complete Class II. Criterion adopted to classify them as patients at post-peak stage of growth was the evaluation of skeletal maturation stages of the median phalanx of the third finger on carpal radiographs. The patients were considered as patients at post-peak stage of growth when the radiographic interpretation comprised the stage in which the epiphysis did not present the width of the metaphysis up to the stage with complete fusion of epiphysis and metaphysis ${ }^{7,16}$ (Table 1).
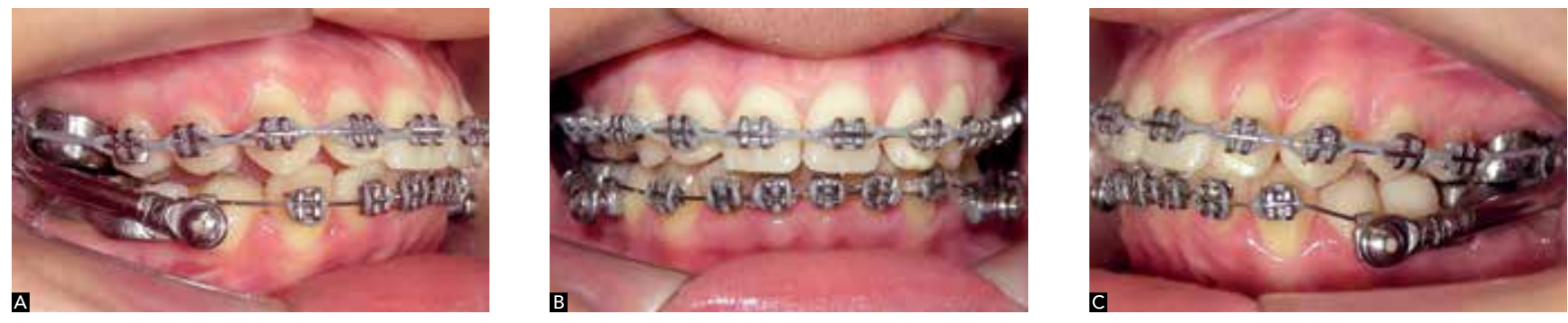

Figure 1 - Herbst appliance (CBJ) combined with fixed appliance: A) right lateral view, B) frontal view, C) left lateral view. 
Table 1 - Detailed description of skeletal maturation stages of patients in the sample.

\begin{tabular}{|c|c|c|c|}
\hline Name & Gender & Initial age & Skeletal maturation stage \\
\hline A.P.F & $\mathrm{F}$ & 20.31 & Rut (complete epiphyseal union in the radius) \\
\hline A.M.S.A & $\mathrm{F}$ & 11.95 & FMui (onset of epiphyseal union in median phalanxes) \\
\hline C.H.F & M & 15.10 & FDut (complete epiphyseal union in distal phalanxes) \\
\hline D.A.R.L & M & 16.18 & Rut (complete epiphyseal union in the radius) \\
\hline F.R & $\mathrm{F}$ & 11.50 & MFDui (onset of epiphyseal union in distal phalanxes) \\
\hline G.P & $\mathrm{F}$ & 12.29 & FMui (onset of epiphyseal union in median phalanxes) \\
\hline G.Q.V & M & 13.90 & FMui (onset of epiphyseal union in median phalanxes) \\
\hline J.F.R & M & 12.03 & MFDui (onset of epiphyseal union in distal phalanxes) \\
\hline J.L & $\mathrm{F}$ & 13.56 & FMui (onset of epiphyseal union in median phalanxes) \\
\hline J.R.C & $\mathrm{F}$ & 16.61 & Rut (complete epiphyseal union in the radius) \\
\hline L.J & $\mathrm{F}$ & 14.01 & FDut (complete epiphyseal union in distal phalanxes) \\
\hline L.F.R & M & 13.13 & FMui (onset of epiphyseal union in median phalanxes) \\
\hline L.P & $\mathrm{F}$ & 35.66 & Rut (complete epiphyseal union in the radius) \\
\hline L.I.M & $\mathrm{F}$ & 27.47 & Rut (complete epiphyseal union in the radius) \\
\hline T.R.V & M & 14.17 & FMui (onset of epiphyseal union in median phalanxes) \\
\hline Y.R.Z.V.A & $\mathrm{F}$ & 14.08 & FDut (complete epiphyseal union in distal phalanxes) \\
\hline
\end{tabular}

All patients in the sample initially received a fixed Roth appliance with $0.022 \times 0.028$-in slot, and the dental arches were aligned and leveled until a $0.019 \times 0.025$-in rectangular stainless steel archwire would passively adapt itself to the slot of all brackets. After alignment and leveling, the Cantilever Bite Jumper (CBJ) appliance was placed to correct the anteroposterior Class II relationship observed between molars. The CBJ is a system composed of four stainless steel crowns, for the maxillary and mandibular first molars, respectively, and a cantilever soldered to the crowns of mandibular first molars, extending itself in the anterior direction towards the premolars and canines, to position the pivot of the mandibular arch. The maxillary pivots are soldered to the external aspect of the maxillary crowns and also constitute the system of telescopic tubes and two pistons, which promotes anterior positioning of the mandible by fixing the appliance with screws. Therefore, the Herbst appliance is indicated for cases with Class II division 1 malocclusion when the main problem is mandibular retrognathism, with anterior teeth without marked crowding or after alignment with fixed orthodontic appliances, preferably with lingually tipped mandibular incisors. ${ }^{14}$ A transpalatal bar in the maxillary arch and a Nance lingual arch in the mandibular arch were placed for anchorage.

\section{Methods}

Lateral cephalograms

In order to evaluate the dentoskeletal changes of the Herbst-CBJ appliance, lateral cephalograms obtained at treatment onset and completion were analyzed. All radiographic images were obtained with the lips at rest and in maximum intercuspation, aided by a Broadbent cephalostat in order to standardize the position of the head. All lateral cephalograms comprising the sample were obtained in three different devices and the magnification of each device was determined for greater accuracy. The different types of devices presented distinct percentages of magnification, ranging from $8.2 \%$ to $11.13 \%$.

\section{Cephalometric tracing and achievement of measurements}

The lateral cephalograms were digitized in a resolution of 9600 x 4800 dpi in a Microtek ScanMaker i800 scanner (Microtek International, Inc., Carson, CA, USA) and connected to a Pentium microcomputer. The images were transferred to the Dolphin Imaging Premium 10.5 software (Dolphin Imaging \& Management Solutions, Chatsworth, CA, USA), through which the cephalometric points of interest were identified and measurements involving planes and lines were obtained. 


\section{Cephalometric measurements (Figs 2 and 3)}

The following cephalometric measurements were used in this study:

1) Maxillary component: SNA, A-Nperp and Co-A.

2) Mandibular component: SNB, P-Nperp and Co-Gn.

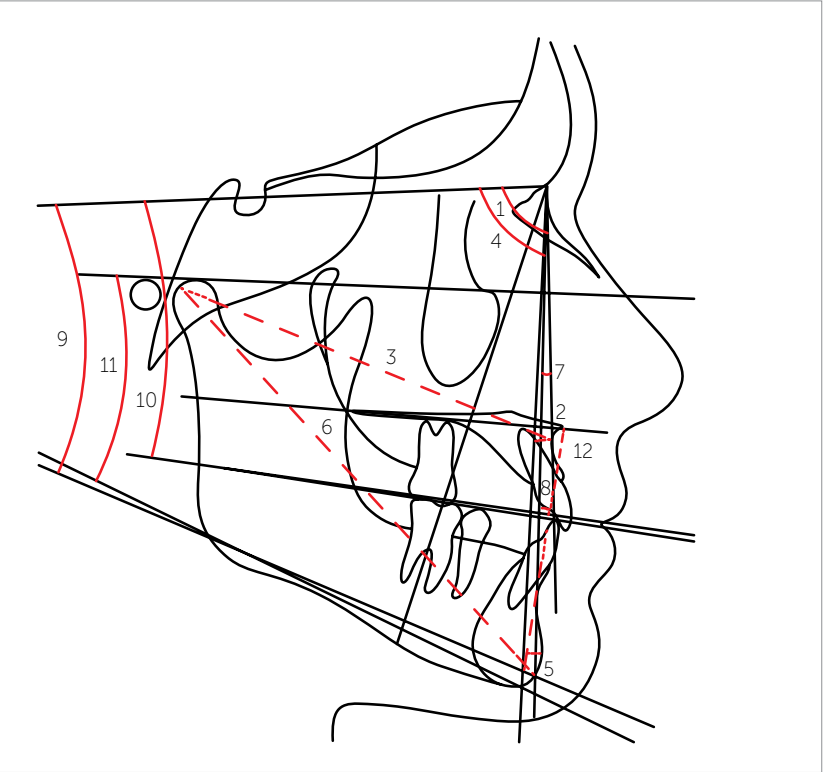

Figure 2 - Skeletal cephalometric measurements: 1) SNA; 2) A-Nperp; 3) Co-A; 4) SNB; 5) P-Nperp; 6) Co-Gn; 7) ANB; 8) Wits; 9) SN.GoGn; 10) SN.Ocl; 11) FMA; 12) LAFH.

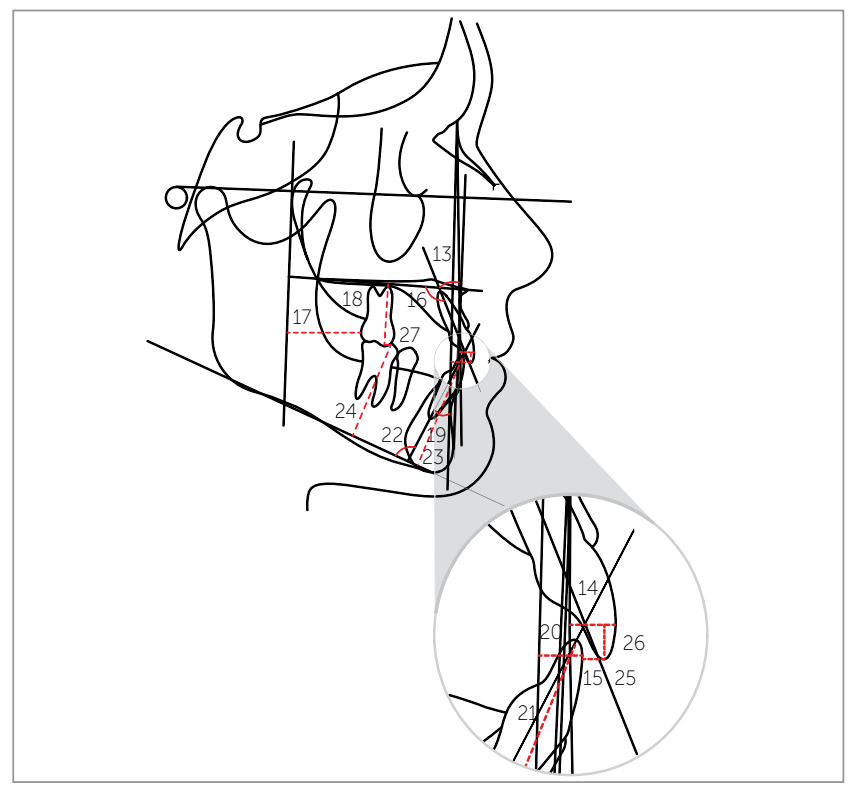

Figure 3 - Dental cephalometric measurements: 13) 1.NA; 14) 1-NA; 15) 1-Aperp; 16) 1-PP; 17) 6-PTV; 18) 6-PP; 19) 1.NB; 20) 1-NB; 21) 1-AP; 22) IMPA; 23) 1-MP; 24) 6-MP; 25) overjet; 26) overbite; 27) molar relationship.
3) Maxillomandibular relationship: ANB and Witts.

4) Growth pattern: SN.GoGn, SN.Ocl, FMA and LAFH.

5) Maxillary dentoalveolar component: 1.NA, 1-NA, 1-Aperp, 1-PP, 6-PTV and 6-PP.

6) Mandibular dentoalveolar component: 1.NB, 1-NB, 1-AP, IMPA, 1-MP and 6-MP.

7) Dental relationships: overjet, overbite and molar relationship.

\section{STATISTICAL ANALYSIS}

\section{Method error}

In order to analyze the intraexaminer error, all measurements were repeated by the same examiner on ten randomly selected lateral cephalograms after a 30-day interval. The application of the Dahlberg formula $\left(\mathrm{Se}^{2}=\Sigma \mathrm{d}^{2} / 2 \mathrm{n}\right)$ allowed estimation of casual errors $^{3}$. Systematic errors were evaluated by the dependent t-test ${ }^{2,6,15}$.

\section{Comparison of cephalometric measurements between initial $\left(T_{1}\right)$ and final $\left(T_{2}\right)$ stages}

The Kolmogorov-Smirnov test was used to verify if the cephalometric data obtained at treatment onset $\left(\mathrm{T}_{1}\right)$ and completion $\left(\mathrm{T}_{2}\right)$ presented normal distribution. The results revealed that some cephalometric variables did not present normal distribution. Thus, the non-parametric Wilcoxon test was applied to compare the changes between initial $\left(\mathrm{T}_{1}\right)$ and final $\left(\mathrm{T}_{2}\right)$ stages. All statistical tests were conducted on the Statistica software for Windows 7.0 (Stat Soft Inc., Tulsa, Oklahoma, USA) and the results were considered statistically significant for $p<0.05$.

\section{RESULTS}

Four variables (SN.GoGn, LAFH, 1.NA and 6-MP) presented systematic error $(\mathrm{p}<0.05)$ and the amplitude of casual errors ranged from 0.13 (1-PP) to 1.25 (A-Nperp).

The results of the Kolmogorov-Smirnov test revealed that the following cephalometric variables did not present normal distribution of data: SNA, SNB and SN.Ocl at treatment onset $\left(\mathrm{T}_{1}\right)$ and SNA, SNB and SN.GoGn in treatment changes $\left(\mathrm{T}_{2}-\mathrm{T}_{1}\right)$ (Table 2$)$.

In Table 3 it can be observed that:

" The maxillary component was not influenced by the treatment performed with the Herbst appliance. 
Table 2 - Kolmogorov-Smirnov test result for initial $\left(T_{1}\right)$ and final values $\left(T_{2}\right)$ as well as changes $\left(T_{2}-T_{1}\right)$ for the experimental group.

\begin{tabular}{|c|c|c|c|c|c|c|}
\hline & \multicolumn{2}{|c|}{ Initial $\left(\mathrm{T}_{1}\right)$} & \multicolumn{2}{|c|}{ Final $\left(\mathrm{T}_{2}\right)$} & \multicolumn{2}{|c|}{ Changes $\left(T_{2}-T_{1}\right)$} \\
\hline & d & $\mathbf{p}$ & d & $\mathbf{p}$ & d & $\mathbf{p}$ \\
\hline \multicolumn{7}{|c|}{ Maxillary component } \\
\hline SNA (degrees) & 0.33720 & $p<0.05$ & 0.16173 & $p>0.20$ & 0.34321 & $p<0.05$ \\
\hline A-Nperp (mm) & 0.15941 & $p>0.20$ & 0.16995 & $p>0.20$ & 0.24383 & $p>0.20$ \\
\hline Co-A (mm) & 0.10683 & $p>0.20$ & 0.11728 & $p>0.20$ & 0.15965 & $p>0.20$ \\
\hline \multicolumn{7}{|c|}{ Mandibular component } \\
\hline SNB (degrees) & 0.40337 & $p<0.01$ & 0.10290 & $p>0.20$ & 0.39996 & $p<0.01$ \\
\hline P-Nperp (mm) & 0.20420 & $p>0.20$ & 0.17342 & $p>0.20$ & 0.15178 & $p>0.20$ \\
\hline Co-Gn (mm) & 0.15385 & $p>0.20$ & 0.14390 & $p>0.20$ & 0.15145 & $p>0.20$ \\
\hline \multicolumn{7}{|c|}{ Maxillomandibular relationship } \\
\hline ANB (degrees) & 0.13175 & $p>0.20$ & 0.18423 & $p>0.20$ & 0.09585 & $p>0.20$ \\
\hline Wits (mm) & 0.22433 & $p>0.20$ & 0.09771 & $p>0.20$ & 0.18087 & $p>0.20$ \\
\hline \multicolumn{7}{|c|}{ Growth pattern } \\
\hline SN.GoGn (degrees) & 0.32505 & $p<0.10$ & 0.17289 & $p>0.20$ & 0.42607 & $p<0.01$ \\
\hline SN.Ocl (degrees) & 0.34652 & $p<0.05$ & 0.10566 & $p>0.20$ & 0.32497 & $p<0.10$ \\
\hline FMA (degrees) & 0.18584 & $p>0.20$ & 0.21232 & $p>0.20$ & 0.09516 & $p>0.20$ \\
\hline AFAl (mm) & 0.15122 & $p>0.20$ & 0.11475 & $p>0.20$ & 0.12362 & $p>0.20$ \\
\hline \multicolumn{7}{|c|}{ Maxillary dentoalveolar component } \\
\hline 1.NA (degrees) & 0.15410 & $p>0.20$ & 0.16095 & $p>0.20$ & 0.12377 & $p>0.20$ \\
\hline $1-N A(m m)$ & 0.15364 & $p>0.20$ & 0.20399 & $p>0.20$ & 0.25303 & $p>0.20$ \\
\hline 1-Aperp (mm) & 0.13260 & $p>0.20$ & 0.12851 & $p>0.20$ & 0.18649 & $p>0.20$ \\
\hline 1-PP (mm) & 0.15810 & $p>0.20$ & 0.13327 & $p>0.20$ & 0.17488 & $p>0.20$ \\
\hline 6-PTV (mm) & 0.14557 & $p>0.20$ & 0.14972 & $p>0.20$ & 0.16282 & $p>0.20$ \\
\hline 6-PP (mm) & 0.19430 & $p>0.20$ & 0.18014 & $p>0.20$ & 0.16931 & $p>0.20$ \\
\hline \multicolumn{7}{|c|}{ Mandibular dentoalveolar component } \\
\hline 1.NB (degrees) & 0.13551 & $p>0.20$ & 0.09290 & $p>0.20$ & 0.11150 & $p>0.20$ \\
\hline $1-N B(m m)$ & 0.17883 & $p>0.20$ & 0.14686 & $p>0.20$ & 0.11769 & $p>0.20$ \\
\hline 1-AP (mm) & 0.19957 & $p>0.20$ & 0.14227 & $p>0.20$ & 0.10627 & $p>0.20$ \\
\hline IMPA (degrees) & 0.10522 & $p>0.20$ & 0.17987 & $p>0.20$ & 0.15662 & $p>0.20$ \\
\hline $1-M P(m m)$ & 0.18251 & $p>0.20$ & 0.08313 & $p>0.20$ & 0.14496 & $p>0.20$ \\
\hline 6-MP (mm) & 0.13172 & $p>0.20$ & 0.10799 & $p>0.20$ & 0.07635 & $p>0.20$ \\
\hline \multicolumn{7}{|c|}{ Dental relationships } \\
\hline Overjet (mm) & 0.14026 & $p>0.20$ & 0.11879 & $p>0.20$ & 0.14074 & $p>0.20$ \\
\hline Overbite (mm) & 0.15292 & $p>0.20$ & 0.18606 & $p>0.20$ & 0.15800 & $p>0.20$ \\
\hline Molar relationship (mm) & 0.10220 & $p>0.20$ & 0.13571 & $p>0.20$ & 0.14571 & $p>0.20$ \\
\hline
\end{tabular}

" The effective mandibular length (Co-Gn) presented statistically significant increase with the Herbst appliance.

" The Herbst appliance did not provide any improvements in the maxillomandibular relationship.

" The SN.Ocl and LAFH variables presented statistically significant increase, in which the occlusal plane presented clockwise rotation, with consequent increase of vertical dimension.

" The maxillary incisors exhibited statistically sig- nificant extrusion during treatment, as evaluated by the $1-\mathrm{PP}$ variable.

" The mandibular incisors presented buccal tipping and statistically significant protrusion (1.NB, 1-NB and 1-AP).

» The mandibular molars presented statistically significant extrusion (6-MP).

» The overjet, overbite and molar relationship were significantly reduced with treatment. 
Table 3 - Non-parametric Wilcoxon test results of comparison between initial $\left(T_{1}\right)$ and final $\left(T_{2}\right)$ stages for evaluation of treatment changes.

\begin{tabular}{|c|c|c|c|c|c|}
\hline \multirow[t]{2}{*}{ Variables } & \multicolumn{2}{|c|}{$\begin{array}{l}\text { Initial }\left(T_{1}\right) \\
(n=16)\end{array}$} & \multicolumn{2}{|c|}{$\begin{array}{l}\text { Final }\left(T_{2}\right) \\
(n=16)\end{array}$} & \multirow[t]{2}{*}{$\mathbf{P}$} \\
\hline & Median & Dlq & Median & Dlq & \\
\hline \multicolumn{6}{|c|}{ Maxillary component } \\
\hline SNA (degrees) & 83.50 & 7.20 & 81.90 & 4.70 & 0.8361 \\
\hline A-Nperp (mm) & 0.05 & 4.10 & -0.20 & 8.25 & 0.7564 \\
\hline Co-A (mm) & 84.75 & 3.65 & 85.25 & 6.00 & 0.3133 \\
\hline \multicolumn{6}{|c|}{ Mandibular component } \\
\hline SNB (degrees) & 77.90 & 6.50 & 78.05 & 7.05 & 0.1089 \\
\hline P-Nperp (mm) & -8.70 & 9.65 & -8.25 & 11.40 & 0.3794 \\
\hline Co-Gn (mm) & 107.45 & 10.40 & 111.60 & 7.30 & 0.0011 \\
\hline \multicolumn{6}{|c|}{ Maxillomandibular relationship } \\
\hline ANB (degrees) & 6.00 & 3.35 & 4.60 & 3.20 & 0.1401 \\
\hline Wits (mm) & 1.20 & 5.30 & -1.10 & 3.55 & 0.1627 \\
\hline \multicolumn{6}{|c|}{ Growth pattern } \\
\hline SN.GoGn (degrees) & 30.50 & 10.75 & 29.95 & 8.50 & 0.7174 \\
\hline SN.OCl (degrees) & 15.00 & 6.90 & 19.40 & 9.50 & 0.0340 \\
\hline FMA (degrees) & 27.95 & 4.85 & 28.05 & 6.15 & 0.9176 \\
\hline AFAI (mm) & 60.60 & 9.50 & 65.60 & 11.45 & 0.0011 \\
\hline \multicolumn{6}{|c|}{ Maxillary dentoalveolar component } \\
\hline 1.NA (degrees) & 18.95 & 16.25 & 21.15 & 11.45 & 0.2553 \\
\hline 1-NA (mm) & 4.75 & 4.50 & 4.45 & 3.45 & 0.3133 \\
\hline 1-Aperp (mm) & 5.10 & 3.40 & 4.25 & 2.95 & 0.1873 \\
\hline 1-PP (mm) & 27.25 & 7.65 & 28.50 & 6.30 & 0.0299 \\
\hline 6-PTV (mm) & 19.30 & 5.20 & 21.50 & 6.60 & 0.3794 \\
\hline 6-PP (mm) & 17.15 & 3.00 & 18.90 & 3.40 & 0.1961 \\
\hline \multicolumn{6}{|c|}{ Mandibular dentoalveolar component } \\
\hline 1.NB (degrees) & 28.25 & 7.90 & 32.10 & 10.60 & 0.0077 \\
\hline $1-\mathrm{NB}(\mathrm{mm})$ & 6.20 & 3.65 & 7.05 & 3.65 & 0.0340 \\
\hline 1-AP (mm) & 2.00 & 2.75 & 3.80 & 3.25 & 0.0032 \\
\hline IMPA (degrees) & 98.45 & 11.25 & 98.15 & 10.55 & 0.0557 \\
\hline $1-M P(m m)$ & 38.05 & 5.40 & 38.50 & 6.25 & 0.3066 \\
\hline 6-MP (mm) & 26.00 & 3.10 & 28.65 & 3.80 & 0.0011 \\
\hline \multicolumn{6}{|c|}{ Dental relationships } \\
\hline Overjet (mm) & 6.40 & 3.65 & 3.30 & 1.30 & 0.0009 \\
\hline Overbite (mm) & 3.85 & 2.50 & 1.60 & 2.50 & 0.0009 \\
\hline Molar relationship (mm) & 1.20 & 1.55 & -1.35 & 1.80 & 0.0021 \\
\hline
\end{tabular}

\section{DISCUSSION}

Sample selection

The use of fixed functional orthopedic appliances in patients at post-peak stage of growth has been demonstrated in the orthodontic literature. Additionally, the use of these appliances has been encouraged in patients in the descending growth curve. This treatment modality presents some advantages when compared to treatment of patients at pre-peak stage of growth, for instance, a better occlusal stability, due to the fact that all permanent teeth are erupted, thus allowing better intercuspation in a Class I relationship ${ }^{7}$. Moreover, the retention time is reduced because the residual growth after active treatment is smaller ${ }^{7}$. However, the studies found in the literature have been conducted with a small number of patients, 
similarly to this study. ${ }^{1,4,11}$ Notwithstanding, considering the strict inclusion criteria, especially inclusion of patients at post-peak stage of growth, only, and the difficulties inherent in longitudinal studies, a number of 16 patients may be considered satisfactory.

\section{Dentoskeletal changes promoted by treatment}

The cephalometric evaluation of dentoskeletal effects of the treatment revealed that the CBJ does not promote significant restriction of anterior displacement of the maxillary component (Table 3), similarly to previous studies. ${ }^{19}$ However, these effects on the maxilla are not in agreement with other authors who conducted similar studies using fixed functional orthopedic appliances. ${ }^{8,12}$ Distension of the musculature that holds the mandible in constantly advanced position causes transmission of the action of this muscular force in posterior direction on the maxilla, thus promoting restriction of maxillary growth. ${ }^{5}$ This action on the maxilla was not evidenced in this study because all patients in the sample were at post-peak stage of growth and, thereby, the anteroposterior growth of the maxilla had ceased.

Considering the mandibular component, the effective mandibular length (Co-Gn) presented a significant increase of $4.15 \mathrm{~mm}$ between initial $\left(T_{1}\right)$ and final stages $\left(\mathrm{T}_{2}\right)$ (Table 3 ). This result was expected and agrees with previous studies., ${ }^{7,9}$ This increase in mandibular length provided by the appliance presents individual variability and depends on the skeletal maturity of the patients at the onset of orthopedic treatment. ${ }^{4,11}$ The absence of a control group compatible with the patients treated in this study did not allow differentiation between the real effect of the Herbst appliance and the mandibular growth.

In the maxillomandibular relationship, no significant improvements were identified in the bone base relationship, even though the ANB variable presented a slight reduction of $1.40^{\circ}$ (Table 3 ). These results demonstrate that the Herbst appliance, when used at post-peak stage of growth, presents more compensatory action than real correction of the anteroposterior discrepancy in patients with Class II malocclusion. ${ }^{7}$ A previous study demonstrated that, in patients at postpeak stage of growth, 37\% of the correction of Class II molar relationship derives from skeletal changes and $63 \%$ from dental changes, while the overjet involves $27 \%$ of skeletal changes and $73 \%$ of dental changes. ${ }^{7}$
With regard to the growth pattern of the patient, both SN.Ocl and LAFH variables presented statistically significant increase, suggesting clockwise rotation of the occlusal plane with consequent increase in vertical dimension (LAFH) (Table 3). These results agree with previous findings that reported increase in vertical dimension of the patient due to treatment performed with the Herbst appliance. ${ }^{8,12}$ The Herbst appliance was constructed in modified occlusion with increase of the interocclusal space between the posterior teeth, which is common in the fabrication of such appliance, thus allowing extrusion of posterior teeth with consequent increase in vertical dimension and clockwise mandibular rotation. ${ }^{10} \mathrm{Ad}-$ ditionally, the mandibular molars (6-MP) exhibited significant extrusion of $2.65 \mathrm{~mm}$ (Table 3 ).

The evaluation of the maxillary dentoalveolar component did not reveal any significant changes in the tipping and position of maxillary incisors, except for the 1-PP variable that evidenced significant extrusion of these teeth with the treatment (Table 3). Considering the effects on maxillary molars, the results demonstrated that these teeth did not present significant changes both in horizontal (6-PTV) and vertical directions (6-PP) (Table 3). A previous study revealed distal movement of $0.5 \mathrm{~mm}$ of the maxillary incisors, which was less important to the correction of the molar relationship and overjet. ${ }^{9}$

The evaluation of the mandibular dentoalveolar component revealed that the mandibular incisors presented significant and marked buccal tipping (1.NB) as well as protrusion of these teeth in the mandible (1-NB and 1-AP). The mandibular molars also exhibited significant extrusion with the treatment (6-MP), which explains more clearly the clockwise rotation of the occlusal plane and the increase of $5.00 \mathrm{~mm}$ in the LAFH (Table 3).

The inclination and protrusion of mandibular incisors is widely reported in the literature and occurs as a function of the telescopic mechanism of the Herbst appliance which produces a force directed towards the mandibular anterior region and the mandibular teeth. ${ }^{7,8,12,13,16}$

The treatment effects are more evident in the evaluation of dental relationships. The significant reductions in overjet of $3.10 \mathrm{~mm}$, in overbite of $2.25 \mathrm{~mm}$ and in molar relationship of $2.55 \mathrm{~mm}$ are changes that 
contribute to the correction of anteroposterior and vertical discrepancies in patients with Class II malocclusion (Table 3). These results are a consequence of the combination of dental and skeletal changes promoted by the Herbst appliance ${ }^{7,12}$.

\section{CONCLUSION}

Based on the present results, it was concluded that effects of treatment performed with the Herbst appliance in patients at post-peak stage of growth are of predominantly dentoalveolar nature.

\section{REFERENCES}

1. Bakke M, Paulsen HU. Herbst treatment in late adolescence: clinical, electromyographic, kinesiographic, and radiographic analysis of one case. Eur J Orthod. 1989:11(4):397-407.

2. Baumrind S, Frantz RC. The reliability of head film measurements. 1. Landmark identification. Am J Orthod. 1971;60(2):111-27.

3. Dahlberg G. Statistical methods for medical and biological students. New York: Interscience; 1940

4. Hansen K, Pancherz H, Hagg U. Long-term effects of the Herbst appliance in relation to the treatment growth period: a cephalometric study. Eur J Orthod. 1991;13(6):471-81.

5. Hirzel HC, Grewe JM. Activators: a practical approach. Am J Orthod 1974:66(5):557-70

6. Houston WJ. The analysis of errors in orthodontic measurements. Am J Orthod. 1983;83(5):382-90.

7. Konik M, Pancherz H, Hansen K. The mechanism of Class II correction in late Herbst treatment. Am J Orthod Dentofacial Orthop. 1997:112(1):87-91

8. Pancherz H. Treatment of Class II malocclusions by jumping the bite with the Herbst appliance. A cephalometric investigation. Am J Orthod. 1979:76(4):423-42

9. Pancherz $\mathrm{H}$. The mechanism of Class II correction in Herbst appliance treatment. A cephalometric investigation. Am J Orthod. 1982;82(2):104-13.

10. Pancherz $\mathrm{H}$. The Herbst appliance: its biologic effects and clinical use. Am J Orthod. 1985:87(1):1-20

11. Pancherz H, Hagg U. Dentofacial orthopedics in relation to somatic maturation. An analysis of 70 consecutive cases treated with the Herbst appliance. Am J Orthod. 1985:88(4):273-87

12. Pancherz H, Hansen K. Occlusal changes during and after Herbst treatment: a cephalometric investigation. Eur J Orthod. 1986;8(4):215-28.
13. Purkayastha SK, Rabie AB, Wong R. Treatment of skeletal Class I malocclusion in adults: stepwise vs single-step advancement with the Herbst appliance. World J Orthod. 2008;9(3):233-43.

14. Quaglio CL, Henriques RP, Henriques JFC, Freitas MRd. Classe II divisão 1 associada à deficiência transversal maxilar. Tratamento com disjuntor tipo Hyrax e aparelho de Herbst: relato de caso clínico. Rev Dental Press Ortod Ortop Facial. 2009;14(5):118-28.

15. Richardson A. A comparison of traditional and computerized methods of cephalometric analysis. Eur J Orthod. 1981;3(1):15-20.

16. Ruf S, Pancherz H. Dentoskeletal effects and facial profile changes in young adults treated with the Herbst appliance. Angle Orthod. 1999:69(3):239-46.

17. Ruf S, Pancherz H. Orthognathic surgery and dentofacial orthopedics in adult Class II division 1 treatment: mandibular sagittal split osteotomy versus Herbst appliance. Am J Orthod Dentofacial Orthop. 2004;126(2):140-52 quiz 254-5.

18. Ruf S, Pancherz H. Herbst/multibracket appliance treatment of Class II division 1 malocclusions in early and late adulthood. A prospective cephalometric study of consecutively treated subjects. Eur J Orthod. 2006:28(4):352-60.

19. Sidhu MS, Kharbanda OP, Sidhu SS. Cephalometric analysis of changes produced by a modified Herbst appliance in the treatment of Class I division 1 malocclusion. Br J Orthod. 1995:22(1):1-12

20. Wieslander L. Intensive treatment of severe Class II malocclusions with a headgear-Herbst appliance in the early mixed dentition. Am J Orthod. 1984;86(1):1-13.

21. Wieslander L. Long-term effect of treatment with the headgear-Herbst appliance in the early mixed dentition. Stability or relapse? Am J Orthod Dentofacial Orthop. 1993:104(4):319-29 